\title{
A STUDY OF THE QUANTITATIVE FRAGILITY TEST IN CHILDREN
}

\author{
BY
}

JANET CORMICK, M.B., Ch.B., D.C.H.

(From the Department of Paediatrics, Glasgow University, and the Royal Hospital for Sick Children, Glasgow)

Although in recent years great advances have been made in the classification and diagnosis of the anaemias, those of haemolytic origin still present unusual difficulties. The etiology of many of these is unknown and they form a composite group from which as investigations proceed clinical entities are separated. Acholuric jaundice is one such entity. The first description of the syndrome was given by Minkowsky (1900) who emphasized the familiar nature of the disease characterized by anaemia, jaundice, excess urobilinuria and increased bile pigment in the blood.

In 1907, Chauffard noted that in this condition the erythrocytes in comparison with those of normal blood showed a diminished resistance (or increased fragility) to saline, and this for a time came to be recognized as pathognomonic of the disease. Following on this discovery the fragility of the red cells was determined by various methods, all of them qualitative. Such a test is still employed. The method most commonly in use consists in the preparation of varying strengths of saline ranging from 0.38 per cent. to 0.60 per cent. at 0.02 per cent. intervals. The accuracy of the sodium chloride solution should be verified by standardizing with a silver nitrate solution of known strength. Approximately equal quantities of the cells to be examined are added to each of the saline dilutions, the resulting solutions being thoroughly mixed and allowed to stand overnight. The supernatant fluid in the lower dilutions becomes tinged with pink due to the freeing of haemoglobin from the lysed cells and the degree of haemolysis is estimated merely by noting the depth of this colour and the amount of sediment remaining in the bottom of the tubes. Normally, haemolysis is complete in a solution of 0.38 per cent. saline, and is just perceptible in a solution of 0.48 per cent. Where increased fragility of the red cells is present, haemolysis is apparent in more concentrated solutions.

The test described is rough and a more delicate method of demonstrating minor departures from normal is desirable, especially because fragility may be increased in certain acute haemolytic anaemias and returns to normal when haemolysis ceases (Parsons and Hawksley, 1933), and acholuric jaundice may exhibit normal erythrocyte fragility (Dawson, 1931 ; Gännslen, 1922). Gännslen quotes a family in which acholuric jaundice occurred, 10 per cent. of those affected showing no alteration in erythrocyte fragility, but details of the method 
of estimation are not given. With a qualitative method, the presence of a small number of unduly fragile cells may not be recognized. Some cases of haemolytic anaemia which do not fall into any recognized group may exhibit a slight increase in red cell fragility which remains undetected by a rough test.

In 1923 Simmel published an account of a quantitative method which he had evolved. The test consists of a series of erythrocyte counts, using varying strengths of a specially prepared solution as the diluting agents, the difference in the counts indicating the number of cells haemolysed. This method has been employed, with minor modifications, by Whitby and Hynes (1935) in healthy adults, but few observations have been made in children. In order to define the limits of normality in children and to attempt to assess the value of the method, quantitative fragility tests have been carried out in a series of normal young children and in certain cases of diseases of the blood, especially the haemolytic anaemias.

\section{Method}

The method used was based on that described by Simmel. The fluid which he employed in preparing the diluting solutions had the same osmotic pressure as blood plasma, and the salts present were in the same proportion as they occurred in the blood, viz:-

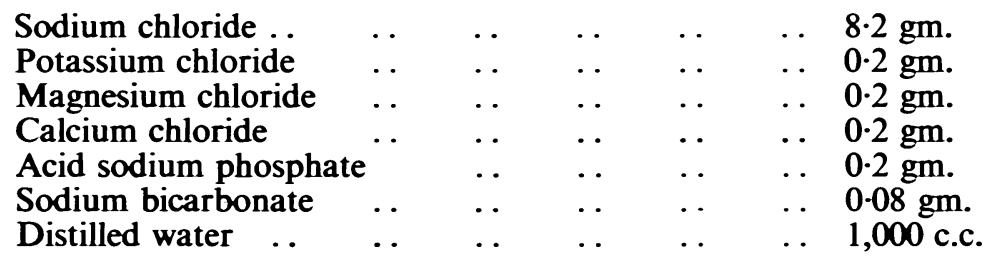

As the excessive haemolysis occurring in haemolytic anaemias has been shown by Bergenhem and Fähraeus (1936), amongst others, to depend not on the salts present in the plasma but on the presence of lysolecithin, the estimation of the fragility of the cells in any solution of salts is purely an artificial test. Consequently there appears to be no reason for employing a haemolysing fluid which necessitates such elaborate preparation, and the solutions suggested by Whitby and Hynes were employed, namely varying strengths of sodium chloride. If the test were to be employed routinely, it would become too laborious if the degree of haemolysis occurring in numerous dilutions had to be estimated, so eight dilutions at 0.05 per cent. intervals, ranging from 0.35 per cent. to 0.70 per cent. were considered adequate for clinical work. The solutions were standardized with 0.15 per cent. silver nitrate and were found to keep in tightly stoppered bottles for one month. Capillary blood was taken from a puncture on the heel, care being taken that no pressure was exerted at the site of the wound. Dilutions of 1 in 200 were made with the various sodium chloride solutions in red cell pipettes, which then stood at room temperatures for one hour. The non-haemolysed erythrocytes in three samples of each dilution were then counted in a Thoma counting chamber, the averages being taken as the final readings. An erythrocyte count of the patient's blood was also done using Hayem's diluting fluid, and the number of cells haemolysed in the several dilutions expressed as a percentage of the total erythrocyte count. 


\section{Normal erythrocyte fragility}

For the study of the average erythrocyte fragility and the limits of normality, fifty children who had been admitted to hospital suffering from complaints other than those related to the haemopoietic system were selected. In each instance the estimations were carried out when the child was fit for dismissal from hospital and in none of the cases was there any known family history of diseases of the blood. The ages of the children ranged from two weeks to twelve years, and the results, which are recorded in age groups in table 1, show the percentage of red cells haemolysed in the various dilutions.

TABLE 1

INDICATING THE AVERAGE ERYTHROCYTE FRAGILITY IN THE VARIOUS AGE GROUPS EXAMINED

\begin{tabular}{|c|c|c|c|c|c|c|c|c|c|c|}
\hline \multirow{3}{*}{\multicolumn{2}{|c|}{ AGE GROUP (YEARS) }} & \multirow{3}{*}{$\begin{array}{l}\text { NO. OF } \\
\text { CHILDREN }\end{array}$} & \multicolumn{8}{|c|}{ ERYTHROCYTE HAEMOLYSIS PER CENT. } \\
\hline & & & \multicolumn{8}{|c|}{ SALINE：GM. PER CENT. } \\
\hline & & & 0.35 & 0.40 & 0.45 & 0.50 & 0.55 & 0.60 & 0.65 & $0 \cdot 70$ \\
\hline $\begin{array}{lll}2 & 52-3 & 12 \\
3 & 12-6 & 12 \\
6 & 12-1 \\
1-2 & \\
2-6 & \\
6 & -12\end{array}$ & $\begin{array}{l}\cdots \\
\cdots \\
\cdots \\
\cdots \\
\cdots\end{array}$ & $\begin{array}{r}4 \\
6 \\
8 \\
7 \\
6 \\
19\end{array}$ & $\begin{array}{l}98 \\
95 \\
93 \\
94 \\
94 \\
96\end{array}$ & $\begin{array}{l}89 \\
82 \\
82 \\
83 \\
81 \\
77\end{array}$ & $\begin{array}{l}69 \\
89 \\
37 \\
47 \\
56 \\
46\end{array}$ & $\begin{array}{l}28 \\
14 \\
17 \\
10 \\
11 \\
12\end{array}$ & $\begin{array}{l}3 \\
1 \\
1 \\
0 \\
0 \\
0\end{array}$ & $\begin{array}{l}0 \\
0 \\
0 \\
0 \\
0 \\
0\end{array}$ & $\begin{array}{l}0 \\
0 \\
0 \\
0 \\
0 \\
0\end{array}$ & $\begin{array}{l}0 \\
0 \\
0 \\
0 \\
0 \\
0\end{array}$ \\
\hline \multicolumn{3}{|c|}{ Average of 50 children } & 95 & 81 & 47 & 14 & 1 & 0 & $\mathbf{0}$ & 0 \\
\hline
\end{tabular}

The average degree of haemolysis occurring in the various dilutions, charted as a curve (fig. 1) corresponds closely with the average curve compiled

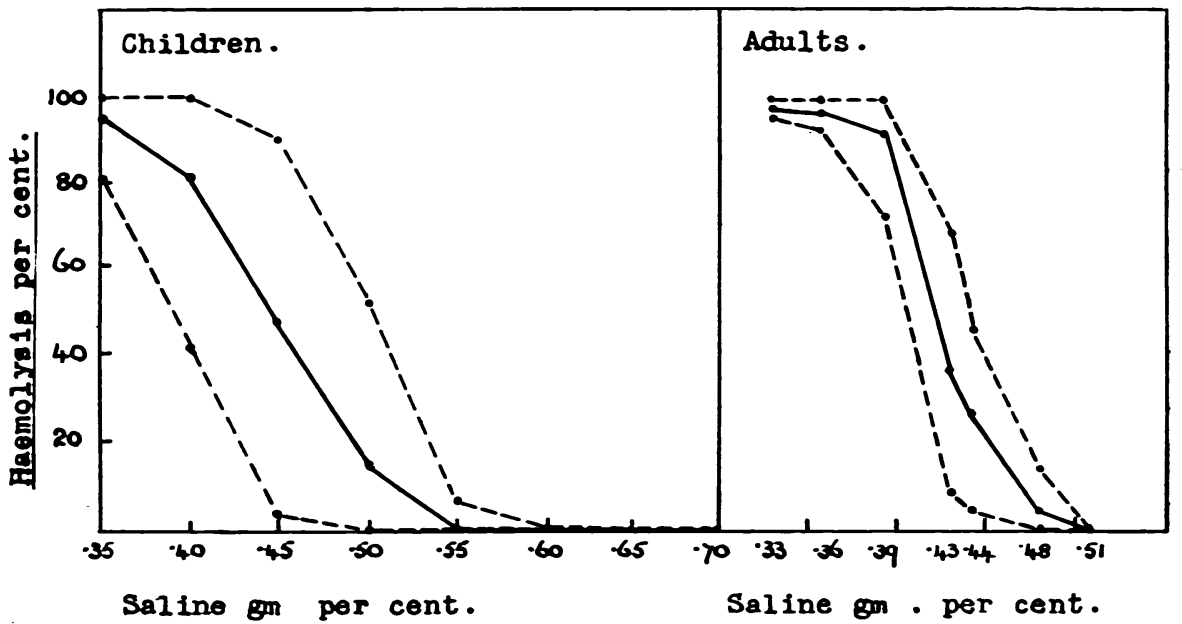

FIG. 1.-Comparing the limits of erythrocyte fragility in children with the limits in adults (Whitby and Hynes). 
by Whitby and Hynes for adults. For comparison with their results, the degree of variability was similarly calculated by using $4 \times$ standard deviation. The range calculated in this way from a small series of figures will include most possible results. Eleven of the children showed erythrocyte haemolysis of over 20 per cent. in the 0.50 per cent. solution. This increased degree of haemolysis could not be explained and occurred irrespective of age although two children below three months were included.

A study of the foregoing series of results shows the range of dilutions in which partial haemolysis occurs to be relatively constant in the groups of children examined, though there is a tendency for haemolysis to extend into the more concentrated solutions in the youngest age group, i.e. two weeks to three months. This apparent increase in erythrocyte fragility in early infancy may be a partially erroneous impression as the number of children in the youngest age groups was smaller than in the older groups, but the possibility that the age factor might influence the erythrocyte fragility in infancy was considered. An increase in fragility at birth which gradually diminishes during the first week of life, has been shown to occur by Goldbloom and Gottlieb (1929). In order to discover how long this increase persists, qualitative fragility tests were made on four apparently healthy infants at two-day intervals from birth till two weeks old. There was no excessive jaundice and the erythrocyte counts were within normal limits for that age. The averages of the results obtained in these four cases are given in table 2.

TABLE 2

SHOWING THE AVERAGE DEGREE OF ERYTHROCYTE HAEMOLYSIS IN VARIOUS SALINE SOLUTIONS IN FOUR INFANTS AT TWO-DAY INTERVALS FROM BIRTH UNTIL TWO WEEKS OLD

\begin{tabular}{|c|c|c|c|c|c|c|c|c|}
\hline \multirow{3}{*}{ DAY OF LIFE } & \multicolumn{8}{|c|}{ ERYTHROCYTE HAEMOLYSIS PER CENT. } \\
\hline & \multicolumn{8}{|c|}{ SALINE GM. PER CENT. } \\
\hline & $0-3$ & 0.40 & 0.45 & $0-50$ & 0.55 & 0.60 & $0-65$ & $0-70$ \\
\hline $\begin{array}{r}1 \\
3 \\
5 \\
7 \\
9 \\
11 \\
13\end{array}$ & $\begin{array}{l}79 \\
79 \\
91 \\
83 \\
90 \\
91 \\
92\end{array}$ & $\begin{array}{l}77 \\
73 \\
81 \\
68 \\
72 \\
79 \\
80\end{array}$ & $\begin{array}{l}64 \\
41 \\
34 \\
38 \\
52 \\
50 \\
50\end{array}$ & $\begin{array}{l}46 \\
38 \\
40 \\
22 \\
24 \\
14 \\
12\end{array}$ & $\begin{array}{r}29 \\
10 \\
20 \\
20 \\
20 \\
10 \\
5\end{array}$ & $\begin{array}{l}\mathbf{0} \\
\mathbf{0} \\
\mathbf{0} \\
\mathbf{0} \\
\mathbf{0} \\
\mathbf{0} \\
\mathbf{0}\end{array}$ & $\begin{array}{l}\mathbf{0} \\
\mathbf{0} \\
\mathbf{0} \\
\mathbf{0} \\
\mathbf{0} \\
\mathbf{0} \\
\mathbf{0}\end{array}$ & $\begin{array}{l}0 \\
0 \\
0 \\
0 \\
0 \\
0 \\
0\end{array}$ \\
\hline
\end{tabular}

At birth there is a decrease in the degree of fragility of the red cells in the lower concentrations of saline, and a tendency for an increase in haemolysis to occur in the more concentrated solutions, that is, there are some cells more resistant than usual and others more fragile. On subsequent days the degree of haemolysis gradually altered until by the eleventh day of life it approached that found in older children. It may be concluded that there is no correlation 
between the variation of the erythrocyte fragility and the age of the child beyond, say, the first two weeks of life.

That carbon dioxide will increase the fragility of the red cells has been shown by Whitby and Hynes, who estimated the fragility of venous and arterial blood, and of blood saturated with carbon dioxide. Erythrocyte fragility was therefore estimated in the capillary blood from the heel of three healthy children, $(a)$ before, and $(b)$ after inhibiting venous return for two minutes. The resulting average alteration in fragility is indicated in table 3 . There is both a quantitative and qualitative increase in fragility during venous stasis, more cells being haemolysed in the higher dilutions and haemolysis extending to the lower dilutions. The results of this experiment show that in the estimation of erythrocyte fragility, the findings may be influenced by other factors than those of pathological significance. False positive results may be obtained if great care is not taken to avoid venous stasis when collecting the samples of blood, and in children this is specially important as venous congestion can be more easily produced in the limb of a child than of an adult.

TABLE 3

SHOWING THE AVERAGE ALTERATION IN ERYTHROCYTE FRAGILITY IN THREE CHILDREN FOLLOWING VENOUS STASIS

\begin{tabular}{|c|c|c|c|c|c|c|c|c|c|}
\hline \multirow{3}{*}{ CAPILLARY BLOOD } & & \multicolumn{8}{|c|}{ ERYTHROCYTE HAEMOLYSIS PER CENT, } \\
\hline & & \multicolumn{8}{|c|}{ SALINE GM. PER CENT. } \\
\hline & & 0.35 & $0 \cdot 40$ & 0.45 & 0.50 & 0.55 & 0.60 & 0.65 & 0.70 \\
\hline (a) Before venous stasis . & .. & 94 & 90 & 50 & 17 & 0 & 0 & 0 & 0 \\
\hline (b) After venous stasis & .. & 96 & 97 & 93 & 48 & 20 & 0 & $\mathbf{0}$ & 0 \\
\hline
\end{tabular}

Fragility tests in children with non-haemolytic anaemia

The material investigated under this heading consists of twelve cases of iron-deficiency anaemia, three of thrombocytopenic purpura and one each of lymphatic leukaemia, Banti's syndrome and lymphadenoma. The results are shown in table 4.

The only case in which any material departure from the normal was encountered was the child aged six years with lymphatic leukaemia. The reticulocyte count was 1.4 per cent. and no urobilin was found in the urine. There was an increase in the degree of haemolysis although the range was normal.

\section{Fragility tests in children with haemolytic anaemia}

It is in this group that a study of the quantitative fragility test becomes of the greatest interest and in which it might be of the greatest help in diagnosis. Two cases of acholuric jaundice were investigated by the quantitative method, 
both before and after splenectomy and the results obtained are most conclusive, a marked increase in erythrocyte fragility being present in both cases, which became less marked following splenectomy. Although the qualitative test in such cases also left no room for doubt, the quantitative test has a greater finality. In one case of a mild haemolytic anaemia corresponding to the type referred to as von Jaksch's, the fragility was within normal limits.

TABLE 4

INDICATING THE QUANTITATIVE FRAGILITY TESTS IN VARIOUS DISEASES AND IN TWO UNCLASSIFIED CASES (G.H. and M.F.)

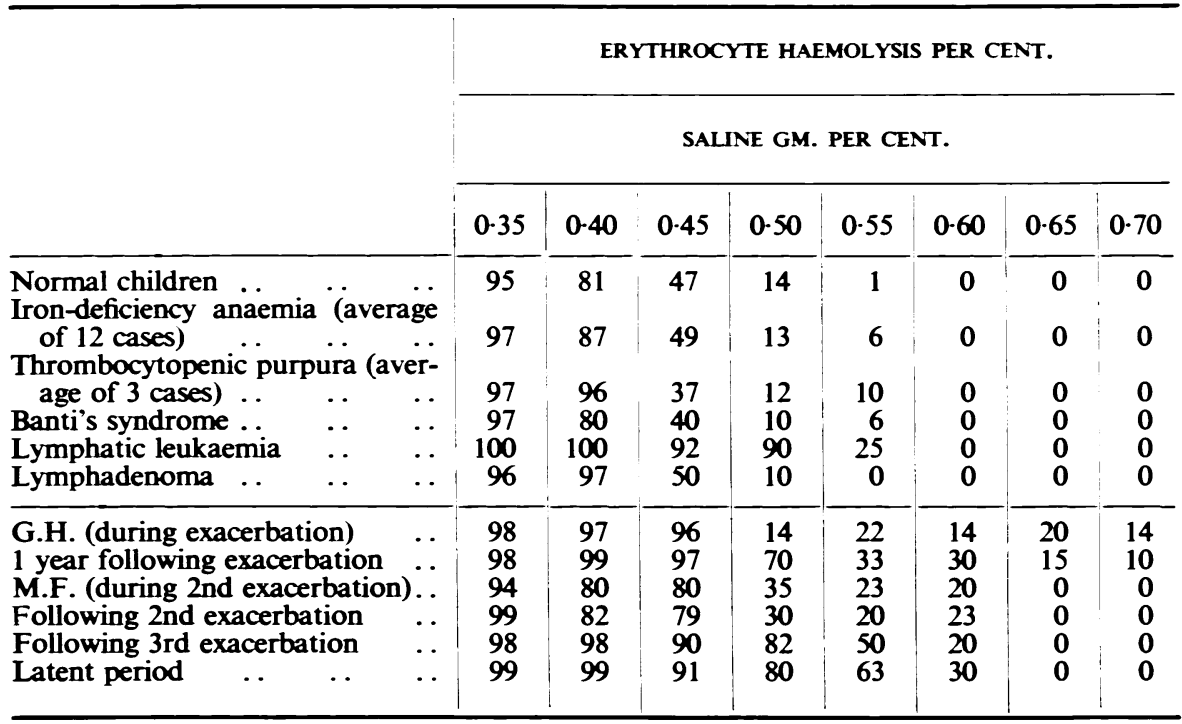

Three cases of congenital haemolytic anaemia were studied. All were admitted to hospital during the first week of life. An extreme degree of anaemia, recticulocytosis, splenomegaly and excessive urobilinuria indicated that pathological haemolysis was occurring. Quantitative fragility tests done in the second week of life gave normal results. The actual figures of these tests are omitted for the sake of brevity.

Two further cases of haemolytic anaemia which were studied have remained unclassified. Although the quantitative fragility test in both cases complicated rather than simplified any attempts made to classify them, it did reveal an increase in fragility which might have been overlooked had a qualitative method of estimation been employed. The results of erythrocyte fragility estimations in these children are shown in table 4.

G.H., aged 10 years. Nothing relevant in family history. No previous illnesses. On admission she gave a history of increasing weakness and pallor during the previous six weeks, and complained of abdominal pain. Blood examination on admission was as follows : red blood cells 890,000 per c.mm., haemoglobin 30 per cent. (Sahli), reticulocytes 36 per cent. Qualitative fragility test showed no apparent haemolysis in solutions beyond 0.52 per cent. sodium chloride, whilst 
a quantitative test revealed haemolysis (14 per cent.) in a solution of 0.70 per cent. sodium chloride. Urine examination showed urobilin ++ . No immediate improvement followed transfusion of paternal blood, but haemolysis ceased spontaneously eleven days later.

One year later, when the girl was apparently well, the reticulocyte count being normal and tests for urobilin being negative, a quantitative fragility test showed that the increase in fragility had persisted, haemolysis still being apparent in a $0 \cdot 70$ per cent. solution.

The complexity of the haemolytic anaemias becomes evident when any attempt is made to classify this case. A history of a relatively sudden onset accompanied by abdominal pain is suggestive of Lederer's anaemia. The erythrocyte fragility, however, which may be temporarily increased while haemolysis is occurring in this type of anaemia rapidly returns to normal with cessation of haemolysis. In the absence of evidence of increased fragility as shown by the quantitative test, this child would have been classed in this group. The persistent increase in cell fragility suggests a diagnosis of acholuric jaundice, though there is nothing in the family history to suggest this. It is conceivable that cases of slight increase in fragility such as shown by this child but with no clinical evidence of excessive haemolysis may exist. Such cases would pass unrecognized unless a quantitative fragility test was done.

M.F. First child. Nothing relevant in the family history. She was first admitted at the age of thirteen months on account of severe anaemia, and at that time was found to have a congenital heart lesion. Blood examination showed severe anaemia with normal colour index and marked reticulocytosis. A blood transfusion was given and she was dismissed home on ferrous sulphate which was given at intervals throughout the course of her illness. Exacerbations of the anaemia occurred at the ages of seventeen months, two years three months and two years nine months. On each occasion she responded to blood transfusion, though at no time did her reticulocyte count fall within normal limits, and the presence of urobilin was noticed on several occasions. During her third admission, cyanosis and digital clubbing were evident and a skiagram of the lung showed marked congestion. The spleen was at no time palpably enlarged and her Wassermann reaction was negative. A fourth exacerbation occurred at three-and-a-half years, which did not respond to repeated blood transfusions, and the child died.

Post-mortem examination revealed a congenital heart lesion (pulmonic stenosis), but threw no light on the etiology of the anaemia.

Quantitative fragility tests done during and after the first three exacerbations of the anaemia, and subsequently during a latent period, indicated an increase in erythrocyte fragility which appeared to progress with the increase in cyanosis.

\section{Conclusions}

Quantitative fragility tests carried out on normal children are comparable with those obtained in adults except in the first week of life, when there is a slight decrease in haemolysis in the lower saline concentrations and a tendency for haemolysis to extend to the more concentrated solutions. The test will reveal alterations in erythrocyte fragility which would be overlooked by a qualitative estimation. 
Cyanosis, with a rise in the carbon dioxide content of the blood, increases not only the degree of haemolysis in the various saline dilutions but also to a slight extent the range of solutions in which haemolysis occurs. Consequently the importance of the test depends as much on the range of solutions in which haemolysis occurs as on the degree of haemolysis in the various dilutions.

Thanks are due to Dr. Stanley Graham for the helpful advice and criticism and to Professor G. Fleming, Dr. Graham and Mr. M. White for the facilities afforded for completing these investigations.

This work was carried out during the tenure of a Muirhead Scholarship.

\section{REFERENCES}

Bergenhem, B., and Fähraeus, R. (1936). Z. ges. exp. Med., 97, 555.

Chauffard, A. (1907). Sem. méd., Paris, 28, 25.

Dawson of Penn (1931). Brit. med. J., 1, 921.

Gännslen, M. (1922). Dtsch. Arch. klin. Med., 140, 210.

Goldbloom, A., and Gottlieb, R. (1929). Amer. J. Dis. Child., 38, 57.

Minkowski, O. (1900). Verh. Kongr. inn. Med., 18, 316.

- (1904). Z. klin. Med., 55, 34.

Parsons, L. G., and Hawksley, J. C. (1933). Arch. Dis. Childh., 8, 184.

Simmel, H. (1923). Disch. Arch. klin. Med., 142, 252.

Whitby, L. E. H., and Hynes, M. (1935). J. Path. Bact., 40, 219. 